\title{
Severe Complications After Splenic Artery Embolization for Portal Hypertension Due to Hepatic Cirrhosis
}

This article was published in the following Dove Press journal: Risk Management and Healthcare Policy

\section{Lei Zhang (D) \\ Zhan-Guo Zhang \\ Xin Long \\ Fei-Long Liu \\ Wan-Guang Zhang}

Hepatic Surgery Center, Tongji Hospital, Tongji Medical College, Huazhong University of Science and Technology, Wuhan 430030, People's Republic of China

Correspondence: Wan-Guang Zhang Hepatic Surgery Center, Tongji Hospital, Tongji Medical College, Huazhong University of Science and Technology, 1095 Jiefang Avenue, Wuhan 430030 , People's Republic of China

Tel +86-27-836652/3

Fax +86-27-8366285।

Email wgzhuang@medmail.com.cn
Background: Splenomegaly/hypersplenism is one of the most common complications of portal hypertension. Splenic artery embolization (SAE) has been increasingly used for treatment of splenomegaly/hypersplenism. However, few studies focused on the severe complications after embolization. In this paper, we reported 16 cases of severe complications after SAE for portal hypertension.

Methods: From February 2011 to January 2019, 16 cirrhotic patients were diagnosed with severe complications after embolization. The clinical symptoms, therapies and prognosis were analyzed. Results: In these patients, the splenic embolization volume was between $50 \%$ and $70 \%$. Among 16 cases, 7 patients were diagnosed with splenic abscess and/or left subphrenic abscess, suffered from the insistent fever, and eventually underwent the surgical therapy; 6 patients with left refractory pleural effusion, suffered from severe chest distress, and underwent repeated thoracocentesis or thoracic closed drainage; 3 patients with thrombosis in portal vein needed oral warfarin therapy.

Conclusion: In cirrhotic patients, the severe complications after SAE are not uncommon after the procedure. It causes more suffering, prolonged hospital stay and more medical cost in these patients. It was debatable whether this technique was an appropriate technique for portal hypertension due to liver cirrhosis, patients contraindicated for the treatment should be carefully identified to avoid the complications.

Keywords: portal hypertension, hypersplenism, splenic artery embolization, complication

\section{Introduction}

About $57 \%$ of liver cirrhosis and $78 \%$ of primary liver cancer result from chronic hepatitis B virus (HBV) or HCV infections worldwide. ${ }^{1}$ Liver cirrhosis is common in Asian countries and leads to liver function impairment and portal hypertension. ${ }^{2}$ Hypersplenism and bleeding from esophagogastric varices are severe complications of portal hypertension. Treatment alternatives for portal hypertension include pharmacotherapy, liver transplantation, endoscopic sclerotherapy and banding, transjugular intrahepatic portosystemic shunt (TIPS), esophageal transaction, selective or partial shunt and esophagogastric devascularization.

Splenic artery embolization (SAE), as a novel treatment for hypersplenism, has been increasingly used in clinical practice over past decades. SAE has been reported to be indicated for a number of conditions, including hypersplenism secondary to cirrhosis, portal hypertension, splenic vein thrombosis, renal insufficiency, thalassemia, chronic idiopathic thrombocytopenic purpura, variceal bleeding, and portal hypertensive 
gastropathy. ${ }^{3}$ Many studies demonstrated that the SAE was very effective for cirrhotic patients, as shown by increased peripheral blood cell counts. ${ }^{4-6}$ However, few studies focused on the severe complications after SAE. In this study, we reported 16 patients with severe post-SAE complications, and discussed their symptoms, therapies and prognoses.

\section{Subjects and Methods}

\section{Patients}

From February 2011 to January 2019, 16 patients were diagnosed with severe complications after SAE at the Hepatic Surgery Center, Tongji Hospital, Tongji Medical College, Huazhong University of Science and Technology, Wuhan, China. All these patients had a history of cirrhosis ranging from 14 to 20 years. There were 9 male patients and 7 female patients, with an average age of 54.6 years (range 47-72 years). Of them, 11 patients were diagnosed as having hepatitis $\mathrm{B}$ cirrhosis, 3 with hepatitis $\mathrm{C}$ cirrhosis, and 2 with schistosomiasis cirrhosis. All patients had hypersplenism and/or splenomegaly, and 5 reported a history of bleeding from esophagogastric varices. Written informed consents for surgery were obtained from all the subjects. This study was approved by the Institutional Review Board of Tongji Hospital, Tongji Medical College, Huazhong University of Science and Technology.

All these patients underwent SAE in other hospitals. The patients did not receive total but only partial embolization of splenic artery, with the splenic embolization volume ranging from $50 \%$ to $70 \%$. We analyzed their clinical symptoms, treatments and prognoses. The clinical data of the patients are shown in Table 1.

\section{Results}

\section{Complications}

Since we focused only on the severe complications after SAE for portal hypertension, the common complications, such as abdominal pain, vomiting and fever, were not covered in this study. These severe complications included splenic abscess and/or left subphrenic abscess, left refractory pleural effusion and thrombosis in portal vein. Among the 16 patients, 7 with splenic abscess and/or left subphrenic abscess mainly had persistent or intermittent fever lasting 7 days to 1 month. Other symptoms included abdominal pain, anepithymia, weight loss, weakness, anemia, and left pleural effusion. The chief complaint of 6 patients with left refractory pleural effusion was severe chest distress. $50 \%$ of these patients $(3 / 6)$ complained of persistent fever, mild or moderate $\left(\leq 38.5^{\circ} \mathrm{C}\right) .3$ patients had main trunk thrombosis in the portal vein and/or in the splenic vein, and 2 patients suffered from abdominal distension due to massive ascites. Imaging findings of severe complications after SAE are shown in Figure $1 \mathrm{~A}-\mathrm{C}$ and $\mathrm{E}-\mathrm{G}$.

\section{Treatments and Prognosis}

Seven patients with abscess were initially treated by antibiotics, with the antibiotics selected on the basis of drug

Table I Demographic and Clinical Characteristics of 16 Patients with Portal Hypertension

\begin{tabular}{|c|c|c|c|c|c|c|c|c|}
\hline Cases & Age(y) & M/F & Child-Pugh & Virus & Bleeding History & $\begin{array}{l}\text { WBC Counts } \\
\left(\times 10^{9} / \mathrm{L}\right)\end{array}$ & $\begin{array}{l}\text { PLT Counts } \\
\left(\times 10^{9} / \mathrm{L}\right)\end{array}$ & Splenic Length $(\mathrm{cm})$ \\
\hline I & 47 & $M$ & B & B & No & 3.4 & 65 & 28 \\
\hline 2 & 61 & $\mathrm{~F}$ & C & B & Yes & 4.1 & 44 & 25 \\
\hline 3 & 56 & M & B & $S^{a}$ & No & 3.5 & 47 & 34 \\
\hline 4 & 40 & $M$ & B & B & No & 2.9 & 50 & 32 \\
\hline 5 & 68 & $\mathrm{~F}$ & $A$ & B & Yes & 2.5 & 52 & 20 \\
\hline 6 & 43 & M & C & C & No & 1.9 & 37 & 36 \\
\hline 7 & 39 & $\mathrm{~F}$ & B & B & No & 3.2 & 38 & 18 \\
\hline 8 & 55 & $\mathrm{~F}$ & C & $S^{a}$ & Yes & 3.6 & 26 & 24 \\
\hline 9 & 60 & $M$ & B & B & Yes & 2.8 & 39 & 28 \\
\hline 10 & 62 & M & B & C & No & 2.0 & 42 & 28 \\
\hline 11 & 62 & $\mathrm{~F}$ & B & B & Yes & 4.0 & 41 & 42 \\
\hline 12 & 72 & $M$ & C & B & No & 1.6 & 29 & 18 \\
\hline 13 & 44 & $M$ & B & B & No & 2.4 & 38 & 30 \\
\hline 14 & 56 & $M$ & $A$ & B & No & 3.0 & 40 & 35 \\
\hline 15 & 44 & $\mathrm{~F}$ & B & C & No & 1.8 & 61 & 30 \\
\hline 16 & 65 & $F$ & B & B & No & 2.5 & 52 & 28 \\
\hline
\end{tabular}

Abbreviation: $\mathrm{S}^{\mathrm{a}}$, schistosomiasis cirrhosis. 


\section{Pretreatment}
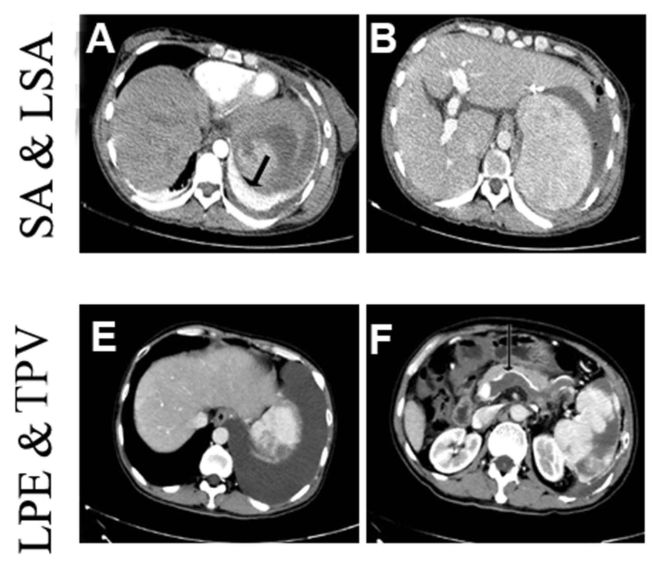

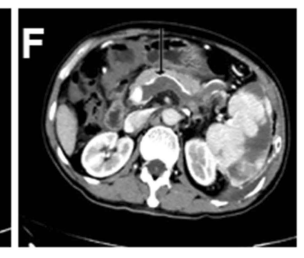

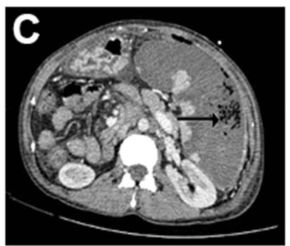

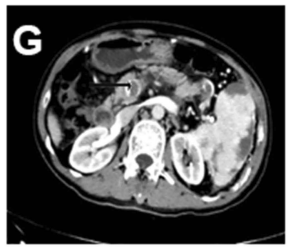

\section{Posttreatment}
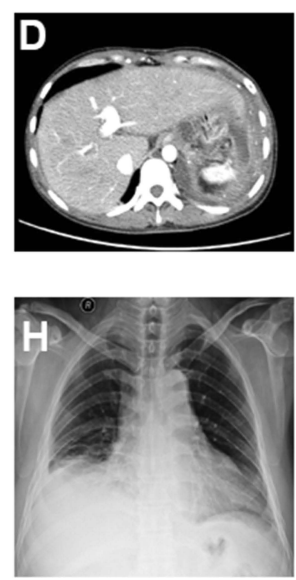

Figure I Imaging findings of severe complications after SAE. A-C show splenic (SA) and left subphrenic abscess (LSA); (A) Incrassation of diaphragm (arrow); (C) Air in the infarcted region (arrow); (D) The abscess is cured by surgery; E- G show left refractory pleural effusion (LPE) and thrombosis in portal vein (TPV); (F) Thrombosis in splenic vein (arrow); (G) Thrombosis in superior mesenteric vein (arrow); (H) The refractory pleural effusion is disappeared after the treatment of repeated thoracocentesis or thoracic closed drainage.

sensitivity tests. Unfortunately, all patients were resistant to antibiotics, even to combination use of antibiotics. Eventually, these patients were treated by surgery, including splenectomy, and/or abscess resection and drainage of left subphrenic abscess (Figure 1D).

The initial treatment for 6 patients with left pleural effusion was thoracocentesis. The puncture fluids were collected for routine pleural fluid examination, bacterial culture and drug sensitivity tests. All patients underwent repeated thoracocentesis and 4 were cured (Figure 1H). Two patients needed thoracic closed drainage, with the drainage time lasting for 1 month and 3 months, respectively.

The three patients with main trunk thrombosis in portal vein were principally treated by anticoagulation with warfarin. The coagulation status was monitored every 5 days. The dosage of warfarin was adjusted according to the result of coagulation examination (The international normalized ratio was maintained between 1.8 and 2.0), and the period of medication was three months. In the 3 patients, portal vein was sonographically examined every 7 days to monitor the change in thrombosis. Diuretics were used when the patients were found to have moderate or massive ascites. If the patients felt postprandial abdominal pain, liquid diet, partial or total parenteral nutrition were provided, or fasting was imposed.

No deaths took place after the proper management and all patients recovered from these serious complications. Complications, treatments and outcomes of 16 patients are shown in Table 2.

\section{Discussion}

In 1973, Maddison performed the first SAE. ${ }^{7}$ A patient with non-alcohol cirrhosis who presented with intractable esophageal variceal bleeding responded well to the treatment and no complications were found in the follow-up period. Since then, as a well-established technique, SAE has been widely used for the treatment of multiple diseases, such as splenic trauma, splenomegaly and/or hypersplenism, esophageal variceal bleeding, splenic artery aneurysms, portal vein occlusion, splenic vein occlusion, splenic artery steal syndrome and splenic neoplasms. ${ }^{8-15}$ A number of studies demonstrated that this method was very effective. The benefits included relieved portal hypertension and hypersplenism, increased hepatic protein synthesis, elevated levels of circulating platelet and leukocytes, and ameliorated hepatic encephalopathy and variceal bleeding. ${ }^{8,15}$ There are two types of SAE - total SAE and partial SAE. Initially, total SAE was performed to treat portal hypertension ${ }^{7}$ and later it was found that total SAE was associated with numerous complications. ${ }^{16}$ Then, partial SAE was designed, performed, and was shown to have significantly better outcomes. Now, partial SAE has become a nonsurgical alternative for cirrhotic patients with hypersplenism who are not indicated for surgical treatment. ${ }^{17}$ Many recent studies have shown that partial SAE is effective and is associated with substantially lower morbidity, complications and mortality. $^{18,19}$

So far, few studies have focused on the post-SAE complications. The previous studies exhibited that the rate of severe complications after SAE for hypersplenism ranged 
Table 2 Complications, Treatments and Outcomes of 16 Patients

\begin{tabular}{|c|c|c|c|c|c|}
\hline Cases & Complication & Treatment & Hospital Stay(d) & TTT(D) & Outcomes \\
\hline 1 & SA & Splenectomy & 15 & 31 & Recovery \\
\hline 2 & LPE & Thoracocentesis & 12 & 12 & Recovery \\
\hline 3 & TPV & Anticoagulation & 10 & 90 & Recovery \\
\hline 4 & SA & Splenectomy & 12 & 15 & Recovery \\
\hline 5 & LPE & Thoracocentesis & 9 & 9 & Recovery \\
\hline 6 & SA/LSA & Splenectomy & 13 & 20 & Recovery \\
\hline 7 & LPE & Thoracic closed drainage & 10 & 60 & Recovery \\
\hline 8 & LPE & Thoracic closed drainage & 8 & 90 & Recovery \\
\hline 9 & TPV & Anticoagulation & 9 & 90 & Recovery \\
\hline 10 & SA & Splenectomy & 12 & 12 & Recovery \\
\hline II & SA & Splenectomy & 11 & 11 & Recovery \\
\hline 12 & LPE & Thoracocentesis & 8 & 8 & Recovery \\
\hline 13 & SA & Splenectomy & 12 & 14 & Recovery \\
\hline 14 & SA/LSA & Splenectomy & 10 & 18 & Recovery \\
\hline 15 & LPE & Thoracocentesis & 6 & 12 & Recovery \\
\hline 16 & TPV & Anticoagulation & 7 & 90 & Recovery \\
\hline
\end{tabular}

Abbreviations: TTT, Total treatment time; SA/LSA, Splenic abscess/left subphrenic abscess; LPE, Left refractory pleural effusion; TPV, thrombosis in portal vein.

from $0 \%$ to $16 \%{ }^{20}$ Koconis et al and Hadduck et al separately reviewed the English language literature on partial SAE. Koconis et al searched articles on SAE or partial SAE from 1973 to $2005^{8,18}$ and found that the complication rate ranged from as low as $1 \%$ to more than $50 \%$, and the overall rate of severe complications was $3.7 \%$. There were 15 types of major complications and the severe complications involved splenic abscess, pulmonary artery embolism, chronic liver failure, bacterial peritonitis, uncontrollable bleeding, pleural effusion and acute pseudo-obstruction of colon. Among those with severe complications, 2 died of splenic abscess, 1 pulmonary artery embolism and 1 chronic liver failure, with a mortality rate of $1 \%$. Hadduck et al collected the papers published from 2005 to 2013. The studies included in this review also revealed many SAE-related complications. The review showed that the overall complication rate varied from $78.1 \%$ to $100 \%$, and the rate of major complications ranged from $10 \%$ to $34.8 \%$. For severe complications, the rate of pleural effusion was from $4.8 \%$ to $10.7 \%$, bacterial peritonitis from $0 \%$ to $4.3 \%$, splenic abscess from $0 \%$ to $6.3 \%$, and portal vein thrombosis from $0 \%$ to $6.3 \%$. Additionally, the mortality rate ranged from $0 \%$ to $6.3 \%$. In the 16 cirrhotic patients with severe post-SAE complications in our series, the splenic embolization volume was between $50 \%$ and $70 \%$, which were optimal as confirmed by many studies. The complications included splenic abscess and/or left subphrenic abscess (7/16), left refractory pleural effusion $(6 / 16)$, main trunk thrombosis in portal vein (3/16). Unfortunately, we could not calculate the rates of these complications in this study. The reasons included: 1) Since these patients came from the different hospitals of this provinces or neighboring regions, it was difficult to count the total number and the rate of cirrhotic patients that underwent SAE; and 2) These patients did not respond to treatments at local hospitals, and there might have been other patients with the same complications who had been cured at local hospitals. On the basis of our findings and literature data, we are led to conclude that severe post-SAE complications and deaths were not rare. With extensive application of SAE, more attention should be paid to SAE-associated complications. Research effort should be directed at how to identify high-risk patients and risk factors for complications after SAE.

Splenic abscess is one of the most common and lifethreatening complications after SAE. The splenic abscess develops possibly because: 1) SAE impairs the immune function of the spleen; ${ }^{19}$ 2) cirrhotic patients tend to be more vulnerable than those with portal hypertension due to other causes; ${ }^{18}$ and 3 ) massive infarction may be subject to bacterial contamination. ${ }^{21}$ Koconis et al showed that the total incidence of splenic abscess in 401 patients was about $1.7 \%$, and the rate ranged from $0 \%$ to $6.3 \%$ in the review of Hadduck et al. The rate of infective complications after SAE, including sepsis, abscess, bacterial peritonitis and pneumonia, seems to be no lower than that of postsplenectomy complications, which was reported to be $4.4 \%$ in children under 16 and $0.9 \%$ in adults respectively. Assal et al reported high rates of complications after SAE 
for hypersplenism in cirrhosis, severe pain (80\%), grade II ascites $(10 \%)$, hematemesis $(10 \%)$, thrombosis in portal vein $(25 \%)$, one death due to splenic abscess $(5 \%){ }^{22}$ A previous study demonstrated that refined SAE with an aseptic technique, antibiotic prophylaxis, and a limited volume of embolized spleen could significantly reduce morbidity and mortality. Patients with large amount of air in the infarcted region after SAE, a large area of cystic necrosis of the spleen, or signs and symptoms suggesting infection are at far greater risk for infection. ${ }^{19,23}$ The diagnosis of splenic abscess principally depends on imaging examinations, such as CT and ultrasonography. What is the most suitable therapeutic approach remains debatable. Some patients need puncture-drainage or -washing management, to evacuate most of the purulent collection and obtain bacterial identification. ${ }^{24,25}$ After treatment, the outcome of the condition is mostly favorable. However, another study showed that percutaneous puncture and drainage could not effectively treat the splenic abscess. ${ }^{26}$ The study of N'Kontchou et al exhibited that two patients with splenic abscess were unsuccessfully treated by drainage of abscess, and they died of septic shock. The reason was recurrent infection due to poor effect of antibiotic therapy because the antibiotics were difficult to penetrate into these cyst lesions. So they suggested early splenectomy if the condition failed to be resolved after percutaneous drainage. Consistent with the opinion of N'Kontchou et al, we believe that antibiotic therapy alone works poorly on splenic abscess. Eventually, these patients underwent surgical treatments, including splenectomy, and/or abscess resection and drainage, and/or left thoracic closed drainage.

The most common severe complication is pleural effusion and/or ascites, which usually develop in the left lung and may be associated with embolization of upper pole of the spleen. Therefore, the researchers recommend embolization of the middle or lower pole of spleen to reduce this complication. $^{8,27,28}$ Mild and moderate left-sided pleural effusions are easily managed with conservative therapy, but severe pleural effusion usually needs to be managed with repeated thoracentesis, even thoracic closed drainage. The length of time could be as long as three months, as shown by our study. Although it is not a dangerous complication, it causes more suffering in these patients, prolonged hospital stay and increased medical costs. Another complication was main trunk thrombosis in portal vein, which was usually found on imaging examinations. Like in splenectomy, it is caused by removal of the splenic venous contribution to portal flow, leading to subsequent reduction of blood flow in the portal vein and a rapid increase in the platelet count after excessive embolization. ${ }^{19,26,29}$ Portal vein thrombosis should be treated by anticoagulation, as most practitioners advocate, ${ }^{8}$ though $\mathrm{Zhu}$ et al suggested that thrombosis requires no special management. ${ }^{30}$

In conclusion, these severe complications are not uncommon after SAE. Once these complications occur, the patients may suffer more, stay in hospital longer and incur more medical cost. Some severe complications even lead to death. The complications that are potentially lifethreatening deserve more attention. New strategies, including methods and embolic materials, are needed to prevent or reduce the severe post-SAE complications. Patients contraindicated for the treatment should be carefully identified to avoid the complications. Studies involving large cohort comparing SAE and splenectomy are warranted in the future.

\section{Abbreviations}

HBV, hepatitis B virus; HCV, hepatitis C virus; TIPS, transjugular intrahepatic portosystemic shunt; SAE, splenic artery embolization; SA, splenic abscess; LSA, left subphrenic abscess; LPE, left refractory pleural effusion; $\mathrm{TPV}$, thrombosis in portal vein.

\section{Acknowledgment}

The authors thank MD. Chao-Hong Yu for the linguistic revision.

\section{Disclosure}

The authors report no conflicts of interest in this work.

\section{References}

1. Rehermann B. Pathogenesis of chronic viral hepatitis: differential roles of T cells and NK cells. Nat Med. 2013;19:859-868. doi:10.1038/ nm.3251

2. Schuppan D, Afdhal NH. Liver cirrhosis. Lancet. 2008;371:838-851. doi:10.1016/S0140-6736(08)60383-9

3. Pålsson B, Hallén M, Forsberg AM, Alwmark A. Partial splenic embolization: long-term outcome. Langenbecks Arch Surg. 2003;387:421-426. doi:10.1007/s00423-002-0342-6

4. Mousa A, Armbruster J, Adongay J, AbuRahma AF. Splenic artery embolization as a treatment option for chronic pancytopenia secondary to hypersplenism: a case report and review of literature. Vasc Endovascular Surg. 2012;46:501-503. doi:10.1177/1538574412453347

5. He XH, Li WT, Peng WJ, Li GD, Wang SP, Xu LC. Total embolization of the main splenic artery as a supplemental treatment modality for hypersplenism. World J Gastroenterol. 2011;17:2953-2957. doi:10.3748/ wjg.v17.i24.2953

6. Pang X, Li T, Wang C. Splenic artery embolization with detachable balloons for hypersplenism. J Int Med Res. 2018;46:4111-4119. doi: $10.1177 / 0300060518786419$ 
7. Yamamoto J, Nagai M, Smith B, et al. Hand-assisted laparoscopic splenectomy and devascularization of the upper stomach in the management of gastric varices. World J Surg. 2006;30:1520-1525. doi:10.1007/s00268-005-0243-2

8. Hadduck TA, McWilliams JP. Partial splenic artery embolization in cirrhotic patients. World J Radiol. 2014;6:160-168. doi:10.4329/wjr. v6.i5.160

9. Dasgupta N, Matsumoto AH, Arslan B, Turba UC, Sabri S, Angle JF. Embolization therapy for traumatic splenic lacerations. Cardiovasc Intervent Radiol. 2012;35:795-806. doi:10.1007/s00270-011-0186-y

10. Pena AH, Kaplan P, Ganesh J, Clevac E, Marie Cahill A. Partial splenic embolization in a child with Gaucher disease, massive splenomegaly and severe thrombocytopenia. Pediatr Radiol. 2009;39:1006-1009. doi:10.1007/s00247-009-1303-9

11. Loffroy R, Guiu B, Cercueil JP, et al. Transcatheter arterial embolization of splenic artery aneurysms and pseudoaneurysms: short- and long-term results. Ann Vasc Surg. 2008;22:618-626. doi:10.1016/j. avsg.2008.02.018

12. Piffaretti G, Tozzi M, Lomazzi C, et al. Splenic artery aneurysms: postembolization syndrome and surgical complications. Am J Surg. 2007;193:166-170. doi:10.1016/j.amjsurg.2006.09.007

13. Wang YB, Zhang JY, Zhang F, Zhao Y, Gong JP. Partial splenic artery embolization to treat hypersplenism secondary to hepatic cirrhosis: a meta-analysis. Am Surg. 2017;83(3):274-283.

14. Cheng YF, Chen CL, Chen TY, et al. Splenic embolization in treatment of portal vein occlusion deferring liver transplantation. Hepatogastroenterology. 2003;50:1614-1616.

15. Chao CP, Nguyen JH, Paz-Fumagalli R, Dougherty MK, Stockland AH. Splenic embolization in liver transplant recipients: early outcomes. Transplant Proc. 2007;39:3194-3198. doi:10.1016/j.transproceed.2007. 07.089

16. Castaneda-Zuniga WR, Hammerschmidt DE, Sanchez R, Amplatz K. Nonsurgical splenectomy. Am J Roentgenol. 1977;129:805-811. doi:10.2214/ajr.129.5.805

17. Ou MC, Chuang MT, Lin XZ, Tsai HM, Chen SY, Liu YS. A novel method for the angiographic estimation of the percentage of spleen volume embolized during partial splenic embolization. Eur J Radiol. 2013;82:1260-1265. doi:10.1016/j.ejrad.2013.01.013

18. Koconis KG, Singh H, Soares G. Partial splenic embolization in the treatment of patients with portal hypertension: a review of the English language literature. J Vasc Intervent Radiol. 2007;18:463-481. doi:10.1016/j.jvir.2006.12.734
19. Yoshida H, Mamada Y, Taniai N, Tajiri T. Partial splenic embolization. Hepatol Res. 2008;38:225-233. doi:10.1111/hep.2008.38.issue-3

20. Hayashi H, Beppu T, Masuda T, et al. Predictive factors for platelet increase after partial splenic embolization in liver cirrhosis patients. J Gastroenterol Hepatol. 2007;10:1638-1642.

21. Alwmark A, Bengmark S, Gullstrand P, Joelsson B, Lunderquist A, Owman T. Evaluation of splenic embolization in patients with portal hypertension and hypersplenism. Ann Surg. 1982;196:518-524. doi:10.1097/00000658-198211000-00003

22. Assal F, El Kassas M, Esmail E, et al. Microwave ablation in the spleen versus partial splenic artery embolisation: a new technique for hypersplenism in cirrhosis. Arab J Gastroenterol. 2017;18(1):25-29. doi:10.1016/j.ajg.2017.01.001

23. Amin MA. El-Gendy MM, Dawoud IE, Shoma A, Negm AM, Amer TA. Partial splenic embolization versus splenectomy for the management of hypersplenism in cirrhotic patients. World J Surg. 2009;33:1702-1710. doi:10.1007/s00268-009-0095-2

24. Faught WE, Gillbertson JJ, Nelson EW. Splenic abscess: presentation, treatment options, and results. Am J Surg. 1989;158:612-614. doi:10.1016/0002-9610(89)90205-5

25. Sakai T, Shiraki K, Inoue H, et al. Complications of partial splenic embolization in cirrhotic patients. Dig Dis Sci. 2002;47:388-391. doi:10.1023/A:1013786509418

26. N'Kontchou G, Seror O, Bourcier V, et al. Partial splenic embolization in patients with cirrhosis: efficacy, tolerance and long term outcome in 32 patients. Eur J Gastroenterol Hepatol. 2005;17:179-184. doi:10.1097/00042737-200502000-00008

27. Israel DM, Hassall E, Culham JA, Phillips RR. Partial splenic embolization in children with hypersplenism. J Pediatr. 1994;124:95-100. doi:10.1016/S0022-3476(94)70261-6

28. Zhu X, Yang RJ, Wang TW. The effect of transcatheter partial splenic embolization in patients with hepatocellular carcinoma concomitant with hypersplenism. Radiol Pract. 2002;17:214-216.

29. Nounla J, Sorge I, Deckert F, Lenk H, Tröbs RB. Acute portal vein thrombosis after splenic embolization and splenectomy for autoimmune pancytopenia. Eur J Pediatr Surg. 2005;15:358-360. doi:10.1055/s-2005865755

30. Zhu K, Meng X, Li Z, et al. Partial splenic embolization using polyvinyl alcohol particles for hypersplenism in cirrhosis: a prospective randomized study. Eur J Radiol. 2008;66:100-106. doi:10.1016/j.ejrad. 2007.04.010
Risk Management and Healthcare Policy

\section{Publish your work in this journal}

Risk Management and Healthcare Policy is an international, peerreviewed, open access journal focusing on all aspects of public health, policy, and preventative measures to promote good health and improve morbidity and mortality in the population. The journal welcomes submitted papers covering original research, basic science, clinical \& epidemiological studies, reviews and evaluations, guidelines, expert opinion and commentary, case reports and extended reports. The manuscript management system is completely online and includes a very quick and fair peer-review system, which is all easy to use. Visit http://www.dovepress.com/testimonials.php to read real quotes from published authors. 